\begin{tabular}{c}
\hline $\begin{array}{c}\text { Brazilian Journal } \\
\text { of Chemical } \\
\text { Engineering }\end{array}$ \\
\hline
\end{tabular}

ISSN 0104-6632

Printed in Brazil

www.abeq.org.br/bjche

Vol. 27, No. 01, pp. $79-87$, January - March, 2010

\title{
REMOVAL OF LEAD FROM AQUEOUS SOLUTION USING WASTE TIRE RUBBER ASH AS AN ADSORBENT
}

\author{
H. Z. Mousavi ${ }^{1 *}$, A. Hosseynifar ${ }^{1}$, V. Jahed ${ }^{1}$ and S. A. M. Dehghani ${ }^{2}$ \\ ${ }^{1}$ Department of Chemistry, College of Science, Semnan University, Semnan, Iran. \\ E-mail: hzmousavi@semnan.ac.ir \\ ${ }^{2}$ RIPI, West End Entrance Blvd, Olympic Village Blvd, P.O. Box: 14757-3311, Tehran, Iran.
}

(Submitted: September 15, 2009 ; Revised: November 10, 2009 ; Accepted: November 12, 2009)

\begin{abstract}
The purpose of this study was to investigate the possibility of the utilization of waste tire rubber ash (WTRA) as a low cost adsorbent for removal of lead (II) ion from aqueous solution. The effect of different parameters (such as contact time, sorbate concentration, adsorbent dosage, $\mathrm{pH}$ of the medium and temperature) were investigated. The sorption process was relatively fast and equilibrium was reached after about 90 min of contact. The experimental data were analyzed by the Freundlich isotherm and the Langmuir isotherm. Equilibrium data fitted well with the Langmuir model with maximum adsorption capacity of 22.35 $\mathrm{mg} / \mathrm{g}$. The adsorption kinetics was investigated and the best fit was achieved by a first-order equation. The results of the removal process show that the $\mathrm{Pb}$ (II) ion adsorption on WTRA is an endothermic and spontaneous process. The procedure developed was successfully applied for the removal of lead ions in aqueous solutions.

Keywords: Removal; $\mathrm{Pb}^{2+}$; Waste tire rubber ash; Isotherm; Kinetics.
\end{abstract}

\section{INTRODUCTION}

Heavy metals can be introduced into the water by various industries. The heavy metals are of special concern because they pose a significant danger to human health (Babel and Kurniawan, 2003; Bayat, 2002). The safe and effective disposal of industrial wastewater is thus a challenging task for industrialists and environmentalists. The important toxic metals are $\mathrm{Cd}, \mathrm{Zn}, \mathrm{Pb}$ and $\mathrm{Ni}$. These heavy toxic metals enter the water bodies through waste water from metal plating industries and mining, pigments and alloys, electroplating corrosion of galvanized piping and dezincification of brass besides other industrial wastes (Mohan and Pittman, 2006; Anthony and Alison, 2002). Heavy metal-containing water is one of the most toxic industrial wastes. Nowadays, with the exponential increase in population, measures for controlling heavy metal emissions into the environment are essential.

Lead is a heavy, soft, malleable, bluish gray metal. Its common ore is galena, where it occurs in the form of sulphide. Most of the lead in the air comes as aerosols, fumes $\&$ sprays. It is very widely used in din storage batteries and the gasoline auto exhaust from gasoline. Motor vehicle exhaust is the major source of the atmospheric layer in the urban area. Other anthropogenic sources of lead include the combustion of coal, processing and manufacturing of lead products and manufacturing of lead additives. Some lead is also introduced into the atmosphere during incineration of residues of lead containing pesticides. Lead is a systemic poison causing anemia, kidney malfunction, brain tissue damage and even death in extreme poisoning (Acharya et al., 2009; Ho and McKay, 2000).

*To whom correspondence should be addressed 
Removal of pollutants such as lead from wastewater has conventionally been accomplished through a range of chemical and physical processes (Kiran et al., 2007; Cesur and Baklaya, 2007). There are traditional methods of industrial wastewater treatment, such as precipitation, adsorption and coagulation methods. However, these processes can be expensive and not fully effective. Among the available techniques, sorption has been used as one of the most practical methods and recent studies have focused on the search for an inexpensive and efficient adsorbent (Yadanaparthi et al., 2009). A wide variety of materials such as chitosan, granular red mud (Zhu et al., 2007), sugar beet pulp (Pehlivan et al., 2008), rice husk (Wong et al., 2003), rice bran Montanher et al., 2005; Ajmal et al., 2003), activated carbon (Giraldo and MorenoPiraján, 2008), Zeolite (Stylianou et al., 2007), sawdust (Asadi et al., 2008), cocoa shells (Meunier et al., 2003), Sargassum (Silva et al., 2003) and leaves (King et al., 2006) are examples of low-cost materials used in the removal of heavy metals.

Currently, fly ash is generally dumped in landfills. Some applications of fly ash in road construction, cement production, and zeolite synthesis have been widely used. However, fly ash recycling is still not sufficient and novel applications have to be explored. In the past a few years, utilization of fly ash as a low-cost adsorbent for removal of pollutants such as heavy metals, dyes, and phenolic compounds in wastewater streams has been tested. Some scientific workers have used modified fly ash (Nascimento et al., 2009) for removal of pollutants from water and wastewater (Gitari et al., 2008; Sharma et al., 2007; Hsu et al., 2008) leading to application of fly ash as adsorbent for water and wastewater reclamation.

Waste tires have been a major management and disposal problem in many countries for decades. In 2004 , over 250 million scrap tires were discarded in the United States and approximately 3 billion waste tires had accumulated in stockpiles. Some of the tires are utilized for rubber tiles and blocks or for cement materials. However, the cost of making rubber powder from a tire is very high. Waste tires are virtually non-degradable and take up landfill spaces (Weng and Chang, 2001). If not properly disposed, waste tires may accumulate water and can subsequently cause the spread of mosquito-borne diseases (Chang, 2008). Often tire fires occur and cause serious air, water, and soil pollution. Nevertheless, tire rubber has a high heat value $(12,000-16,000 \mathrm{Btu} / \mathrm{lb})$. In the United States, Canada, Germany, the United Kingdom, and Japan, waste tires have been used as a supplemental fuel for cement kilns and in paper mills. Therefore, it is of interest to explore any new application/market for the scrap tire reclaiming industry.

This paper describes a study of the use of waste tire rubber ash (WTRA) as an adsorbent for removal of $\mathrm{Pb}^{2+}$ from aqueous solutions and wastewater samples. The effect of various important parameters on removal such as $\mathrm{pH}$, heavy metal concentrations and fly ash dosages, contact time and temperature is also discussed. It was found that waste tire rubber ash is an excellent adsorbent for removal of lead and has several advantages over other materials.

\section{EXPERIMENTAL}

\section{Materials}

All chemicals are reagent grade and were used as received without further purification. All solutions were prepared with deionized water. Metal solutions were prepared by dissolving the appropriate amount of $\mathrm{Pb}\left(\mathrm{NO}_{3}\right)_{2}$ (Merck) in distilled water. $0.1 \mathrm{M} \mathrm{NaOH}$ and $\mathrm{HNO}_{3}$ solutions were used for $\mathrm{pH}$ adjustment. A Metrohm $\mathrm{pH}$ meter (Model E-632) was used for $\mathrm{pH}$ measurements. A Shimadzu (AA680) atomic absorption spectrophotometer (AAS) with lead hollow cathode lamps and air acetylene flame was used for determining $\mathrm{Pb}^{2+}$ ion in solution. A temperature controlled water bath flask shaker was used for shaking all the solutions.

\section{Preparation of Adsorbent}

The waste tires were initially washed with detergent solution and dilute $\mathrm{HCl}$ in order to remove the earthen soil debris. After that, the cleaned and dried waste tire was burned and the residue placed in a porcelain crucible and burnt completely at $500^{\circ} \mathrm{C}$ in a muffle furnace for $2 \mathrm{~h}$. After cooling, a very dilute acidic solution (such as $0.001 \mathrm{~mol} \mathrm{~L}^{-1} \mathrm{HCl}$ ) was used to remove the salts of metals such as sodium, potassium and calcium. Then the mixture was filtered using Whatman grade 42 filter paper. The filtered solid was then washed with $100 \mathrm{~mL}$ of double distilled water and dried at $105^{\circ} \mathrm{C}$ for $2 \mathrm{~h}$ before use.

\section{Characteristics of Adsorbent Material}

The physical properties and chemical composition of the WTRA are presented in Table 1. The morphological characteristics of the adsorbent were evaluated by using a Phillips XL30 Scanning Electron Microscope. The samples of powder of 
WTRA were covered with a thin layer of gold and an electron acceleration voltage of $10 \mathrm{kV}$ was applied. The surface area and adsorption average pore width of the selected fraction of nano alumina was determined by the $\mathrm{N}_{2}$ gas Brunauer-Emmett-Teller method of analysis using a Micromeritics Chemisorption ASAP 2020. The WTRA has a gray color and its specific surface area was $1.88 \mathrm{~m}^{2} / \mathrm{g}$.

\section{Table 1: Chemical analysis of waste tire rubber ash}

\begin{tabular}{|c|r|}
\hline Component & (\%) \\
\hline $\mathrm{SiO}_{2}$ & 26.5 \\
$\mathrm{Fe}_{2} \mathrm{O}_{3}$ & 9.3 \\
$\mathrm{Al}_{2} \mathrm{O}_{3}$ & 8.7 \\
$\mathrm{CaO}$ & 12.9 \\
$\mathrm{MgO}$ & 6.4 \\
$\mathrm{SO}_{3}$ & 1.6 \\
$\mathrm{Na}_{2} \mathrm{O}$ & 1.4 \\
$\mathrm{~K}_{2} \mathrm{O}$ & 1.1 \\
$\mathrm{TiO}_{2}$ & 1.0 \\
$\mathrm{Cl}^{-}$ & 0.1 \\
$\mathrm{Zn}$ & 20.2 \\
Loss on ignition & 10.6 \\
\hline
\end{tabular}

The scanning electron micrographic examination of WTRA particles (Fig.1) shows a highly porous morphology of the waste rubber fly ash with pores of different sizes and shapes. The image also reveals that the external surface is full of cavities, which suggest that WTRA exhibits a high surface area and irregular in shape.

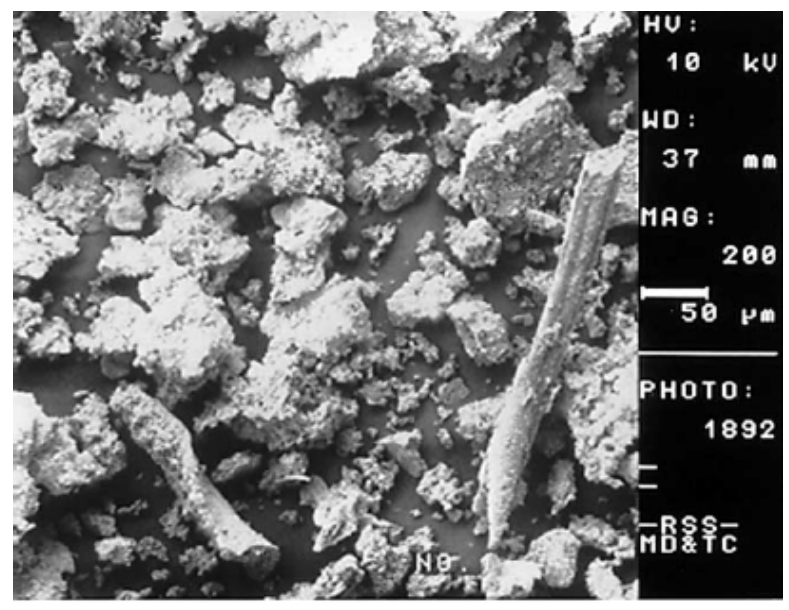

Figure 1: Scanning electron micrographs of WTRA particles

\section{Batch Adsorption Experiments}

Batch adsorption experiments were carried out by mechanically shaking a series of bottles containing $0.05 \mathrm{~g}$ of WTRA sample with $100 \mathrm{ml}$ of an aqueous solution of $\mathrm{Pb}^{2+}$ of the desired concentration, temperature and $\mathrm{pH}$ in different properly cleaned polythene bottles on a shaking thermostat with a constant speed of $100 \mathrm{rpm}$. The bottles were agitated for pre-determinated times until equilibrium was attained. At the end of the agitation period, the mixture was centrifuged at $4200 \mathrm{rpm}$ for $10 \mathrm{~min}$. The progress of adsorption was assessed by determining the residual concentration of $\mathrm{Pb}^{2+}$ in supernatant by an atomic absorption spectrophotometer.

The percent removal of lead ions from aqueous solution was calculated by the following equation:

$\%$ Removal $=\frac{\left(\mathrm{C}_{\mathrm{i}}-\mathrm{C}_{\mathrm{f}}\right)}{\mathrm{C}_{\mathrm{i}}} \times 100$

where $C_{i}$ and $C_{f}$ are the initial and equilibrium concentrations of the adsorbate, respectively. The reported value of $\mathrm{Pb}^{2+}$ ions adsorbed by WTRA in each test was the average of at least three measurements.

\section{RESULTS AND DISCUSSION}

\section{Effect of Contact Time on the Removal of $\mathrm{Pb}^{2+}$}

The effect of contact time on the adsorption of $\mathrm{Pb}^{2+}$ was studied for an initial concentration of 100 $400 \mathrm{mg} \mathrm{L} \mathrm{L}^{-1}$. The contact time experiments were carried out at $25{ }^{\circ} \mathrm{C}$ (time interval, $15 \mathrm{~min}$ ). It is observed from Figure 2 that the adsorption increased with increasing contact time, and the equilibrium was attained after shaking for $90 \mathrm{~min}$. Therefore, for further experiments, the shaking time was set to 90 $\min$.

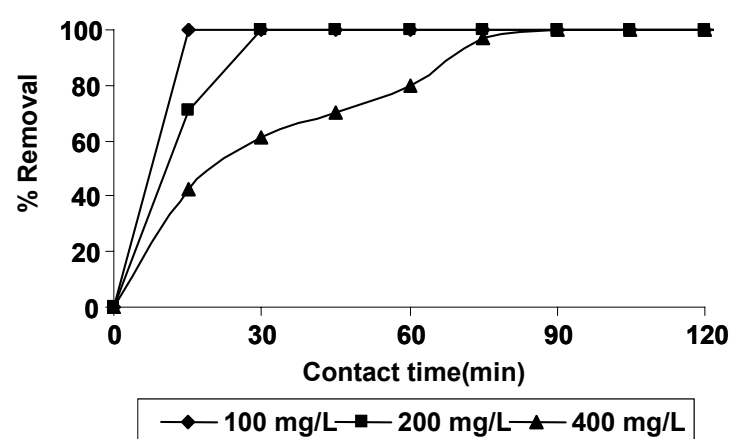

Figure 2: Effect of contact time on the removal of $\mathrm{Pb}$ (II), $2.0 \mathrm{~g} \mathrm{~L}^{-1}$ of WTRA, $100 \mathrm{~mL}$ of $\mathrm{Pb}^{2+}$ solution, temperature $25^{\circ} \mathrm{C}$. 


\section{Effect of Adsorbent Dose}

A dosage study is an important parameter in adsorption studies because it determines the capacity of adsorbent for a given initial concentration of metal ion solution. The effect of adsorbent dose on the percent removal of $\mathrm{Pb}(\mathrm{II})$ at an initial concentration of $400 \mathrm{mg} \mathrm{L}^{-1}$ is shown in Fig. 3. From the figure it can be observed that increasing the adsorbent dose increased the percent removal of $\mathrm{Pb}$ (II) from $28.8 \%$ up to $99.4 \%$ with the required optimum dose of 2 $\mathrm{g} / \mathrm{L}$. Beyond the optimum dose the removal efficiency did not change with the adsorbent dose. As expected, the removal efficiency increased with increasing the adsorbent dose for a given initial metal concentration, because, for a fixed initial adsorbate concentration, increasing adsorbent dose provides greater surface area or more adsorption sites. Further, it can be attributed to the binding of metal ions onto the surface functional groups present on the WTRA. On the other hand, when the WTRA dose increased, the adsorption capacity (the amount adsorbed per unit mass of adsorbent) decreased. The decrease in adsorption capacity with increase in the adsorbent dose is mainly due to the increase of free adsorption sites in the adsorption reaction.

\section{Effect of pH}

It is well known that the removal of heavy metals by adsorbent depends on the $\mathrm{pH}$ of the initial solution. Therefore, in order to establish the effect of $\mathrm{pH}$ on the adsorption of lead (II) ions, the batch equilibrium studies were carried out in different $\mathrm{pH}$ values. The $\mathrm{pH}$ range was chosen as $2-6$ in order to avoid metal hydroxides, which has been estimated to occur at $\mathrm{pH}>6.5$ for $\mathrm{Pb}(\mathrm{OH})_{2}$. Figure 4 shows the amount of lead ions removed from aqueous solution

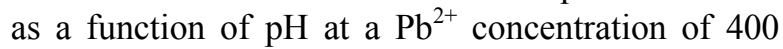
$\mathrm{mg} / \mathrm{L}$. The amount of $\mathrm{Pb}^{2+}$ ions removed from solution increases rapidly from $\mathrm{pH} 4$ to $\mathrm{pH}$. At $\mathrm{pH}$ $4,73.8 \%$ of lead ion was removed, while at $\mathrm{pH} 6$, $93.1 \%$ of lead ion was removed. Above $\mathrm{pH} 6$, the amount of $\mathrm{Pb}^{2+}$ ion removed from the solution by the WTRA, steadily increased to $100 \%$.

$\mathrm{Pb}^{2+}(\mathrm{aq})+\mathrm{nH}_{2} \mathrm{O}=\mathrm{Pb}(\mathrm{OH})_{\mathrm{n}}+\mathrm{nH}^{+}$

At low $\mathrm{pH}$, the surfaces of the WTRA are positive and there was formation of the complex $\left[\mathrm{Pb}(\mathrm{OH})_{4}\right]^{2-}$; hence, the complex formed will be adsorbed on the adsorbent surfaces. Hydroxyl-metal complexes have higher affinity for adsorption than the hydrated metal ion, because the formation of an $\mathrm{OH}$ adduct of the metal ion reduces the free energy required for adsorption (Elliott and Denneny, 1982).

Low sorption at lower $\mathrm{pH}$ could be ascribed to the hydrogen ions competing with metal ions for sorption sites. This means that, at higher $\mathrm{H}^{+}$ concentration, the adsorbent surface becomes more positively charged, thus reducing the attraction between adsorbent and metal ions. In contrast, as the $\mathrm{pH}$ increases, more negatively charged surface become available, thus facilitating greater metal removal. The increase in metal ion uptake by WTRA at higher $\mathrm{pH}$ values may be attributed to calcium content and the $\left(\mathrm{SiO}_{2}+\mathrm{Al}_{2} \mathrm{O}_{3}+\mathrm{Fe}_{2} \mathrm{O}_{3}\right)$ content that provides alkalinity in the system, rising the $\mathrm{pH}$ to strongly alkaline values. The facilitation of the uptake of $\mathrm{Pb}^{2+}$ ions by the WTRA at higher $\mathrm{pH}$ may be related not only to the formation of metal hydroxides but also to the precipitation, which caused a decrease in the rate of adsorption.

\section{Effect of Temperature on Removal of $\mathbf{P b}^{2+}$}

To determine whether the ongoing adsorption process was endothermic or exothermic in nature, $\mathrm{Pb}^{2+}$ adsorption studies over WTRA were carried out between $1-60^{\circ} \mathrm{C}$ for different initial feed concentrations and at constant adsorbent dose of $2.0 \mathrm{~g} / \mathrm{L}$. It can be seen that the adsorption of lead ions increased when the temperature was increased (Fig. 5). For example, at $1^{\circ} \mathrm{C}$ the amount of $\mathrm{Pb}^{2+}$ ion adsorbed was $15 \%$, whereas at $30{ }^{\circ} \mathrm{C}, 92.8$ of $\mathrm{Pb}^{2+}$ ion was adsorbed by WTRA for an initial concentration of $200 \mathrm{mg} / \mathrm{L}$ of $\mathrm{Pb}^{2+}$. It can be seen from Figure 5 that, initially, the percentage removal increases very sharply with the increase in temperature, but beyond a certain value of ca. $30^{\circ} \mathrm{C}$, the percentage removal reaches almost a constant value. The above results also showed that the sorption was endothermic in nature. The increased sorption with the rise of temperature may be diffusion controlled, which is an endothermic process, i.e., the rise of temperatures favors the sorbate transport within the pores of sorbent. The increased sorption with the rise of temperature is also due to the increase in the number of the sorption sites generated because of breaking of some internal bonds near the edges of active surface sites of the sorbent. 


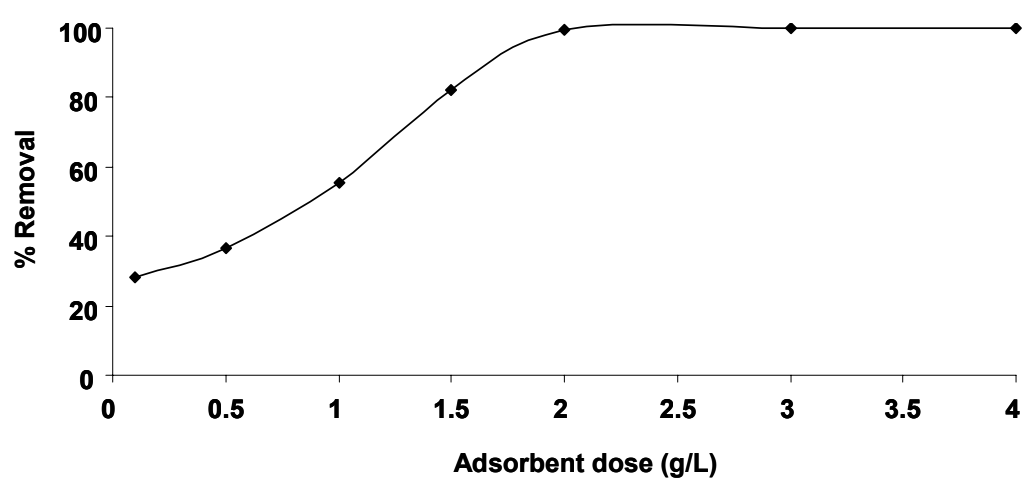

Figure 3: Effect of WTRA dosage on the removal of $\mathrm{Pb}^{2+}$, $100 \mathrm{~mL}$ of solutions, contact time $90 \mathrm{~min}$, temperature $25^{\circ} \mathrm{C}$.

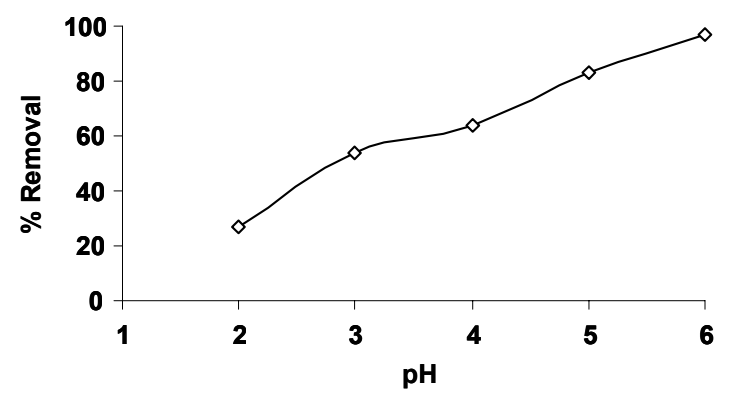

Figure 4: Effect of $\mathrm{pH}$ on the removal of $\mathrm{Pb}^{2+}$ by WTRA: $2.0 \mathrm{~g} \mathrm{~L}^{-1}$ of WTRA, $100 \mathrm{~mL}$ of solution, temperature $25^{\circ} \mathrm{C}$.

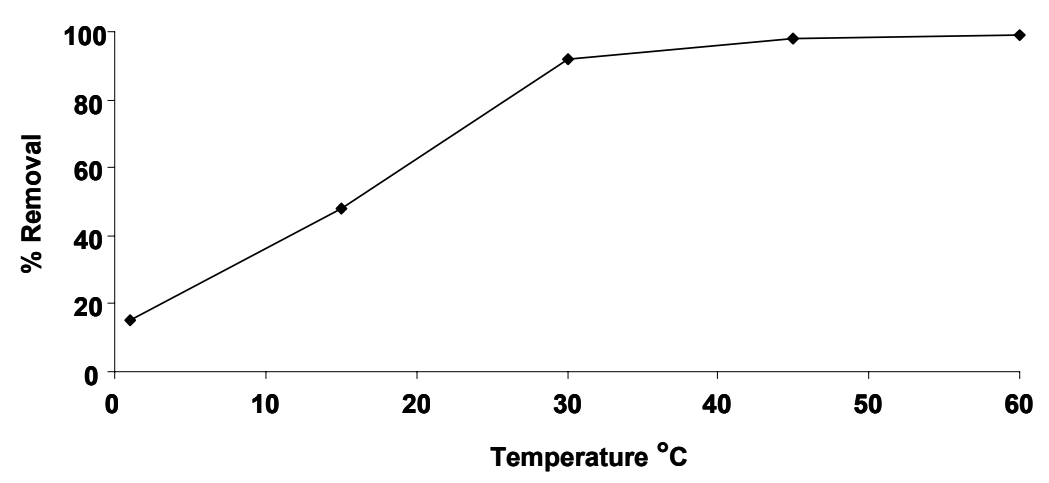

Figure 5: Effect of temperature on the removal of $\mathrm{Pb}^{2+}$ onto WTRA: $2.0 \mathrm{~g} \mathrm{~L}^{-1}$ of WTRA, $100 \mathrm{~mL}$ of solution.

\section{Isotherm Study}

The relationship between the amount of a substance adsorbed per unit mass of adsorbent at constant temperature and its concentration in the equilibrium solution is called the adsorption isotherm. The equilibrium adsorption isotherms are important in determining the adsorption capacity of $\mathrm{Pb}$ (II) metal ions and diagnose the nature of adsorption onto the WTRA. Two theoretical isotherm models were used to fit the experimental data: Langmuir and Freundlich models. The Langmuir and Freundlich sorption isotherms have been commonly used to describe the equilibrium behavior of adsorbate. Curves of related adsorption isotherms are regressed and parameters of the equations are provided. 


\section{Langmuir Isotherm}

The general form of the Langmuir equation is (Langmuir, 1918):

$\frac{\mathrm{Ce}}{\mathrm{Q}}=\frac{1}{\mathrm{Q}_{0} \mathrm{~b}}+\frac{\mathrm{Ce}}{\mathrm{Q}_{0}}$

where $\mathrm{Ce}$ is the equilibrium concentration $\left(\mathrm{mg} \mathrm{L}^{-1}\right)$, $\mathrm{Q}$ is the amount of heavy metals sorbed, $\mathrm{b}$ is the sorption constant $\left(\mathrm{L} \mathrm{mg}^{-1}\right)$ (at a given temperature) related to the energy of sorption, $\mathrm{Q}_{0}$ is the maximum sorption capacity $\left(\mathrm{mg} \mathrm{g}^{-1}\right)$. A linear plot of $\mathrm{Ce} / \mathrm{Q}$ against $\mathrm{Ce}$ is employed to give the values of $\mathrm{Q}_{0}$ and $\mathrm{b}$ from the slope and the intercept of the plot. These parameters, plus the correlation coefficient $\left(\mathrm{R}^{2}\right)$, of the Langmuir equation for the sorption of $\mathrm{Pb}^{2+}$ ions by WTRA are given in Table 2 .

\section{Freundlich Isotherm}

The Freundlich isotherm is an empirical equation employed to describe heterogeneous systems. The Freundlich equation is expressed as (Freundlich, 1906):

$\mathrm{Q}_{\mathrm{e}}=\mathrm{K}_{\mathrm{F}} \mathrm{C}_{\mathrm{e}}^{1 / \mathrm{n}}$

The linear form of the equation can be written as:

$\operatorname{lnqe}=\ln \mathrm{K}_{\mathrm{F}}+(1 / \mathrm{n}) \ln \mathrm{C}_{\mathrm{e}}$

where $\mathrm{K}_{\mathrm{F}}$ and $\mathrm{n}$ are the Freundlich constants related to the adsorption capacity and adsorption intensity, respectively. The intercept and the slope of the linear plot of lnqe versus $\operatorname{lnCe}$ at given experimental conditions provide the values of $\mathrm{K}_{\mathrm{F}}$ and $1 / \mathrm{n}$, respectively.

The correlation coefficient and other parameters obtained for the adsorbent are shown in Table 2, which indicate that the experimental data fitted well to Langmuir model. This suggests that the adsorption of $\mathrm{Pb}^{2+}$ ions by WTRA is of the monolayer-type and agrees with the observation that the metal ion adsorption from an aqueous solution usually forms a layer on the adsorbent surface.

\section{Kinetic Study}

Kinetics of adsorption is an important characteristic in defining the efficiency of adsorption. Various kinetic models have been proposed by different researchers, where the adsorption has been treated as a first order, pseudo-first-order and pseudo-second-order process. Different systems conform to different models. The Lagergren's rate equation is the one most widely used for the sorption of a solute from a liquid solution (Lagergren, 1898). The linear form of the pseudo-firstorder equation, given by:

$\log \left(q_{e}-q_{t}\right)=\log q_{e}-\frac{k t}{2.303}$

where $\mathrm{q}_{\mathrm{e}}$ and $\mathrm{q}_{\mathrm{t}}$ are the amount of $\mathrm{Pb}^{2+}$ adsorbed at equilibrium and at time $\mathrm{t}$, in $\mathrm{mg} / \mathrm{g}$ and $\mathrm{k}$ is the pseudo-first-order rate constant, was applied in the present studies of $\mathrm{Pb}^{2+}$ adsorption. Fig. 6 shows that the data is well described by the Lagergren equation. The plot was found to be linear with good correlation coefficient $\left(R^{2}=0.998\right)$ indicating that Lagergren's model is applicable to lead adsorption on WTRA and that the process is pseudo-first-order. The value of the corresponding pseudo-first-order rate constant $\mathrm{k}$ was evaluated to be $0.0023 \mathrm{~min}^{-1}$.

\section{Application of WTRA for Industrial Wastewater Treatment}

The utilization of WTRA as an adsorbent was assessed by its application in treatment of industrial wastewater samples. Electroplating industry wastewater samples containing $\mathrm{Pb}^{2+}$ were collected from local industries situated in the industrial belt of Semnan city (Iran). The results reveal that the treatment of metal ions in wastewater samples is not significantly different from the results predicted based on single solute batch experiments. Thus, the present study demonstrates that WTRA can be successfully used for the removal of $\mathrm{Pb}^{2+}$ ions from industrial wastewaters.

\section{Comparison of Lead (II) Removal with Different Adsorbents Reported in the Literature}

The adsorption capacities of the adsorbents for the removal of lead (II) have been compared with those of other adsorbents reported in the literature and the values of adsorption capacities are presented in Table 3. The experimental data of the present investigations are comparable with the reported values in some cases. We note that our material (WTRA) is more effective compared to other materials. However, the present experiments are conducted to find the technical applicability of the low-cost adsorbents to treat $\mathrm{Pb}$ (II). 
Table 2: The Langmuir and Freundlich isotherm model constants

\begin{tabular}{|c|c|c|c|c|c|c|}
\hline & \multicolumn{3}{|c|}{ Freundlich } & \multicolumn{3}{c|}{ Langmuir } \\
\cline { 2 - 7 } & $\mathbf{1 / n}$ & $\mathbf{K}_{\mathbf{F}}$ & $\mathbf{R}^{\mathbf{2}}$ & $\mathbf{Q}_{\mathbf{0}}$ & $\mathbf{b}$ & $\mathbf{R}^{\mathbf{2}}$ \\
\hline $\mathrm{Pb}^{2+}$ & 0.23 & 8.23 & 0.965 & 22.35 & 0.274 & 0.995 \\
\hline
\end{tabular}

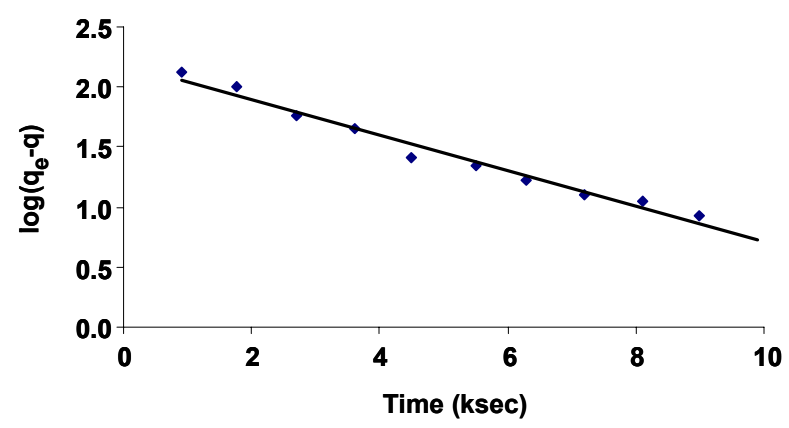

Figure 6: Plot of the pseudo-first order kinetic model for $\mathrm{Pb}(\mathrm{II})$ ion adsorption.

Table 3: Comparison of adsorption capacity with different adsorbents reported in the literature.

\begin{tabular}{|l|c|l|}
\hline Adsorbents & Maximum adsorption capacity, $\left.\mathbf{Q}_{\mathbf{0}} \mathbf{( m g} / \mathbf{g}\right)$ & \multicolumn{1}{c|}{ Reference } \\
\hline Rice husk & 11.0 & Chuah and et al. (2005) \\
Baggase fly ash & 2.5 & Gupta and Ali (2004) \\
Phaseolus aureus hulls & 21.8 & Madhava Rao et al.(2009) \\
Waste tea leaves & 9.0 & Ahluwali and Goyal (2005) \\
This study & 22.35 & \\
\hline
\end{tabular}

\section{CONCLUSIONS}

The present study shows that waste tire rubber ash is an effective adsorbent for the removal of lead ions from aqueous and wastewater solutions. The adsorption of $\mathrm{Pb}^{2+}$ by waste tire rubber ash is a function of the adsorbent dosage, initial concentration of metal ions, $\mathrm{pH}$ and time of contact. Increase in adsorbent dosage leads to an increase in $\mathrm{Pb}$ (II) adsorption due to the increased number of adsorption sites. The kinetic study shows that equilibrium is reached for $\mathrm{Pb}^{2+}$ ions at 90 minutes. The adsorption isotherm studies showed that the Langmuir adsorption isotherm model fits well with the experimental data. The maximum adsorption capacity was obtained for WTRA $(22.35 \mathrm{mg} / \mathrm{g})$. Thermodynamic studies indicated the adsorption process increases with an increase in temperature and the sorption was endothermic in nature. The adsorbent has a high capacity for removal of lead ions from contaminated water and wastewaters and it can be used for removal of $\mathrm{Pb}^{2+}$ from moderately acidic aqueous solutions. The cost of removal is expected to be quite low, as the adsorbents are cheap and easily available in large quantities. The WTRA would be useful in treatment of wastewater containing lead ions.

\section{ACKNOWLEDGEMENT}

The authors thank the Research Council and office of gifted students of Semnan University for their financial support of this work.

\section{REFERENCES}

Acharya, J., Sahu, J. N., Mohanty, C. R., Meikap, B. C., Removal of lead(II) from wastewater by activated carbon developed from Tamarind wood by zinc chloride activation. Chem. Eng. J. 149, No. 1-3, 249 (2009).

Ajmal, M., Rao, R. A. K., Anwar, J. A. and Ahmad, R., Adsorption studies on rice husk: removal and recovery of $\mathrm{Cd}(\mathrm{II})$ from wastewater. Bioresour. Technol. 86, No.2, 147 (2003).

Ahluwali, S. S. and Goyal, D., Removal of Heavy Metals by Waste Tea Leaves from Aqueous Solution. Eng. Life Sci. 5, No. 2, 158 (2005).

Anthony, N. K. and Alison, E. L., A mathematical model of a high sulphate wastewater an aerobic treatment system. Water Res. 36, No. 1, 257 (2002).

Asadi, F., Shariatmadari, H. and Mirghaffari, N., Modification of rice hull and sawdust sorptive 
characteristics for remove heavy metals from synthetic solutions and wastewater. J. Hazard. Mater. 154, No. 1-3, 451 (2008).

Babel, S. and Kurniawan, T. A., Low cost adsorbents for heavy metals uptake from contaminated water. J. Hazard. Mater. 97, No. 1-3, 219 (2003).

Bayat, B., Combined removal of zinc (II) and cadmium (II) from aqueous solutions by adsorption onto high-calcium Turkish fly ash. Water Air Soil Pollut. 136, No. 1-4, 69 (2002).

Cesur, H. and Baklaya, N., Zinc removal from aqueous solution using an industrial by- product phosphogypsum. Chem. Eng. J. 131, No 1, 203 (2007).

Chang, N. B., Economic and policy instrument analyses in support of the scrap tire recycling program in Taiwan. J. Environ. Manage. 86, No. 3, 435 (2008).

Chuah, T. C., Jumasiah, A., Azni, I., Katayan, S. and Choong, S. Y. T., Rice husk as a potentially lowcost biosorbent for heavy metal and dye removal: an overview. Desalination 175, No. 3, 305 (2005).

Elliott, H. A., Denneny, C. M., Soil Adsorption of cadmium from solutions containing organic ligands. J. Environ. Qual. 11, 658 (1982).

Freundlich, H., Adsorption in solution. Phys. Chem. 57, 384 (1906).

Giraldo, L. and Moreno-Pirajan, J. C., $\mathrm{Pb}^{2+}$ adsorption from aqueous solutions on activated carbons obtained from lignocellulosic residues. Braz. J. Chem. Eng. 25, No.1, 143 (2008)

Gitari, W. M., Petrik, L. F., Etchebers, O., Key, D. L. and Okujeni, C., Utilization of fly ash for treatment of coal mines wastewater: Solubility controls on major inorganic contaminants. Fuel 87, No. 12, 2450 (2008).

Gupta, V. K. and Ali, I., Removal of lead and chromium from wastewater using bagasse fly ash - a sugar industry waste. J. Colloid Interf. Sci. 271, No. 2, 321 (2004).

Ho, Y. S., McKay, G., The kinetics of sorption of divalent metal ions onto sphagnum moss peat. Water Res. 34, No. 3, 735 (2000).

Hsu, T. C., Yu, C. C. and Yeh, C. M., Adsorption of $\mathrm{Cu}^{2+}$ from water using raw and modified coal fly ashes. Fuel 87, No. 7, 1355 (2008).

Jianlong, W., Xinmin, Z., Decai, D., Ding, Z., Bioadsorption of lead(II) from aqueous solution by fungal biomass of Aspergillus niger. $\mathrm{J}$. Biotechnol. 87, No. 3, 273 (2001).

Kaczala, F., Marques, M. and Hogland, W., Lead and vanadium removal from a real industrial wastewater by gravitational settling/sedimentation and sorption onto Pinus sylvestris sawdust. Bioresour. Technol. 100, No. 1, 235 (2009).

King, P., Srivinas, N., Kumar, Y. P. and Prasad, V. S., Sorption of copper (II) ion from aqueous solution by Tectona grandis 1.f. (teak leaves powder). J. Hazard. Mater. 136, No. 3, 560 (2006).

Kiran, B., Kaushik, A. and Kaushik, C. P., Response surface methodological approach for optimizing removal of $\mathrm{Cr}(\mathrm{VI})$ from aqueous solution using immobilized cyanobacterium. Chem. Eng. J. 126, No. 2-3, 147 (2007).

Lagergren, S., Zur theorie der sogenannten adsorption geloster stoffe. K. Sven. Vetenskapsakad. Handl. 24, No. 4, 1 (1898).

Langmuir, I. Adsorption of gases on plane surfaces of glass, mica and platinum. J. Am. Chem. Soc. 40, 1361 (1918).

Madhava Rao, M., Ramana, M. D. K., Seshaiah, K., Wang, M. C. and Chien, S. W.C., Removal of some metal ions by activated carbon prepared from Phaseolus aureus hulls. J. Hazard. Mater. 166, No. 2-3, 1006 (2009).

Meunier, N., Laroulandie, J., Blais, J.-F., Dayal Tyagi, R., Lead removal from acidicsolutions by sorption on cocoa shells: effect of some parameters. J. Environ.Eng. 129, No. 8, 693 (2003).

Mohan, D. and Pittman, C. U., Activated carbons and low cost adsorbents for remediation of triand hexavalent chromium from water. J. Hazard. Mater. 137, No. 2, 762 (2006).

Montanher, S. F., Oliveira, E. A., Rollemberg, E. M., Removal of metal ions from aqueous solutions by sorption onto rice bran. J. Hazard. Mater. 117, No. 2-3, 207 (2005).

Nascimento, M., Moreira Soares, P. S., Paulo de Souza, V., Adsorption of heavy metal cations using coal fly ash modified by hydrothermal method. Fuel 88, No 9, 1714 (2009).

Pehlivan, E., Yanık, B. H., Ahmetli, G. and Pehlivan, M., Equilibrium isotherm studies for the uptake of cadmium and lead ions onto sugar beet pulp. Bioresour. Technol. 99, No. 9, 3520 (2008).

Silva, E. A., Cossich, E. S., Tavares, C. G., Cardozo Filho, L., Guirardello, R., Biosorption of binary mixtures of $\mathrm{Cr}(\mathrm{III})$ and $\mathrm{Cu}(\mathrm{II})$ ions by Sargassum sp. Braz. J. Chem. Eng. 20, No.3, 213 (2003).

Sharma, Y. C., Singh, S. N., Paras, A. and Gode, F., Fly ash for the removal of $\mathrm{Mn}$ (II) from aqueous solutions and wastewaters. Chem. Eng. J. 32, No. $1-3,319$ (2007).

Stylianou, M. A., Inglezakis, V. J., Moustakas, K. G., Malamis, S. P. and Loizidou, M. D., Removal 
of $\mathrm{Cu}(\mathrm{II})$ in fixed bed and batch reactors using natural zeolite and exfoliated vermiculite as adsorbents. Desalination 215, No. 1-3, 133 (2007).

Weng, Y. C. and Chang, N. B., Treatment of metal and industrial waste water by fly ash and cement fixation. Resour. Conserv Recycl. 33, 181 (2001). Wong, K. K., Lee, C. K., Low, K. S. and Haron, M. J., Removal of $\mathrm{Cu}$ and $\mathrm{Pb}$ by tartaric acid modified rice husk from aqueous solutions.
Chemosphere 50, No.1, 23 (2003).

Yadanaparthi, S. K. R., Graybill, D., Wandruszka, R., Adsorbents for the removal of arsenic, cadmium, and lead from contaminated waters. J. Hazard. Mater. 171 No 1-3, 1 ( 2009).

Zhu, C., Luan, Z., Wang, Y. and Shan, X., Removal of cadmium from aqueous solutions by adsorption on granular red mud (GRM). Purif. Technol., 57, No. 1, 161 (2007). 